\title{
Educating the Educators: Technology-Enhanced Mathematics Teaching and Learning
}

\author{
Leong Chee Kin \\ SEAMEO RECSAM
}

\begin{abstract}
Educational research has shown that teaching quality is one of the most important factors in raising student achievement. There is a compelling need for educators to keep abreast of the important developments that are taking place in educational arena. One of the educational areas that has massive development is the use of technology to enhance teaching and learning especially in mathematics. This development needs professional development among educators. Being a regional science and mathematics education centre, the Southeast Asian Ministers of Education Organisation Regional Centre for Education in Science and Mathematics (SEAMEO RECSAM) has always been cognizant of the importance of these developments. Its training programmes are planned to incorporate these developments for in-service teachers, teacher educators and ministry of education mathematics officers. As the Centre's mandate aims to ensure that these participants from Southeast Asians countries as well as those from outside the region are equipped with emerging educational technology tools which can enhance teaching and learning of mathematics. This paper will share the Centre's experiences in continuing professional development among mathematics teacher, teacher educators and officers from the ministry of education on educational innovation and technology.
\end{abstract}

Keywords: Educational research, technology, professional development, SEAMEO RECSAM

\section{Introduction}

How can those in the field of education best utilise new technologies? Educators are reminded by phrases such as "emerging technology" and "evolving technologies" that the digital world is continuously changing. There are new devices, new software and altered applications, and shifting practices which keep crossing our horizon as well as quietly appearing in our midst. How do we help educators to keep abreast of these developments to enhance teaching and learning specifically in mathematics?

SEAMEO RECSAM, being one of the 21 regional centres of the Southeast Asian Ministers of Educational Organisation and since its inception in 1967 was mandated to improve science and mathematics education in Southeast Asia. This paper shares certain selected initiatives of the Centre in recent years for helping educators from this region as well as those from outside the region through its continuing professional development programmes. Mainly, this paper will highlight the measures taken to update and equip these educators with emerging educational technology tools which will enhance the teaching and learning of mathematics in classrooms. 


\section{The Training Programmes}

SEAMEO RECSAM enhances the skills and knowledge of its participants on educational technology tools through its training programmes, namely, Regular Courses, Incountry Courses, Customised Courses and Workshops. Regular Courses are designed to address the needs of educators from SEAMEO member countries and its duration is four weeks. In-country Courses are courses conducted in SEAMEO member own county for their teachers and educators for up to five days duration. On the other hand, Customised Courses are tailor-made programmes of varying duration in respond to the special needs of member countries and other agencies which may be held in-country or at the Centre. Workshops are enrichment activities offered by SEAMEO RECSAM to all SEAMEO member countries for their teachers and educators and are conducted at the Centre.

The "emergent educational technology tools" are normally introduced or shared as part of the course content or entirely as a workshop. External experts are invited or the SEAMEO RECSAM specialists will conduct these educational technology tools sessions.

\section{The Teaching Principles and Technological Tools}

The aim of conducting these emergent educational technology tools training sessions is to ensure that the participants of the courses in the Centre which are normally from Southeast Asian countries are exposed to new technological tools and to equip them with the knowledge to utilise these tools to enhance the teaching and learning of mathematics.

Various teaching principles are also shared in these training sessions. It is basically based on the experts who introduce these technology tools. Among these principles are; Motivation to the Topic, Teaching in Context, Demonstration and Visualisation, Discovery or Exploration, and Intensification of Students' Self-preparation.

The following case studies demonstrate some of these technology tools that have been introduced to our participants.

\section{Case 1: Geometer's Sketchpad}

There is a general consensus that the use of information and communication technology (ICT) in teaching and learning brings about positive benefits in student learning. The findings of the impact survey (as in Harrison, Comber, Fisher, Haw, Lwein, Lunzer \& Watling, 2002) provide concrete evidence of ICT having an impact on teaching and learning 
in the classroom. The Geometer's Sketchpad (GSP) is a proven Dynamic Geometry tool appropriate for elementary school, middle school, and high school, giving teachers and students a visual way to explore the range of mathematical ideas and representations (see Battista \& Burrow, 1997, Furner \& Bennet, 1995, and Sinclair \& Jackiw, 2005).

Among other good features of GSP is that it allows the users to explore simple as well as highly complex theorems and relations in Geometry (see Giamatti, 1995), and has the ability to record students' constructions as scripts. The most useful aspect of scripting constructions is that students can test whether their constructions work in general or whether they have successfully discovered a special case. In addition, the GSP software allows mathematics to be learnt and taught in a more creative way (Finzer \& Bennet, 1995)

The Centre managed to convince the Ministry of Education Malaysia to purchase a nationwide license of the Geometer's Sketchpad version 4.0 in 2004. SEAMEO RECSAM has been instrumental in providing support in the form of organising basic to advance training programmes for key personnel on the use of GSP for teaching and learning.

The following Figure 1 is one example of a participant's work using GSP for secondary school students to explore the Standard Normal Distribution.

In 2011, the Centre carried out a survey on the teachers' use of GSP in secondary schools. A total of 208 selected secondary schools in Malaysia were involved in this study. Although, the majority of the respondents rated GSP as an excellent teaching tool in mathematics classrooms, it also revealed some interesting facts. About half of the respondents used GSP in their classrooms at least once a semester (Warabhorn, Devadason, Wahyudi, Cheah \& Teoh, 2012). Most of them used it as a demonstrating tool, where whole class instructions was conducted using one computer. A large number of the GSP users (72.2\%) also reported facing problem using GSP, which ranged from lack of knowledge, inexperience, time constraint and limitation of ICT facilities available in many of those schools (Warabhorn et al., 2012).

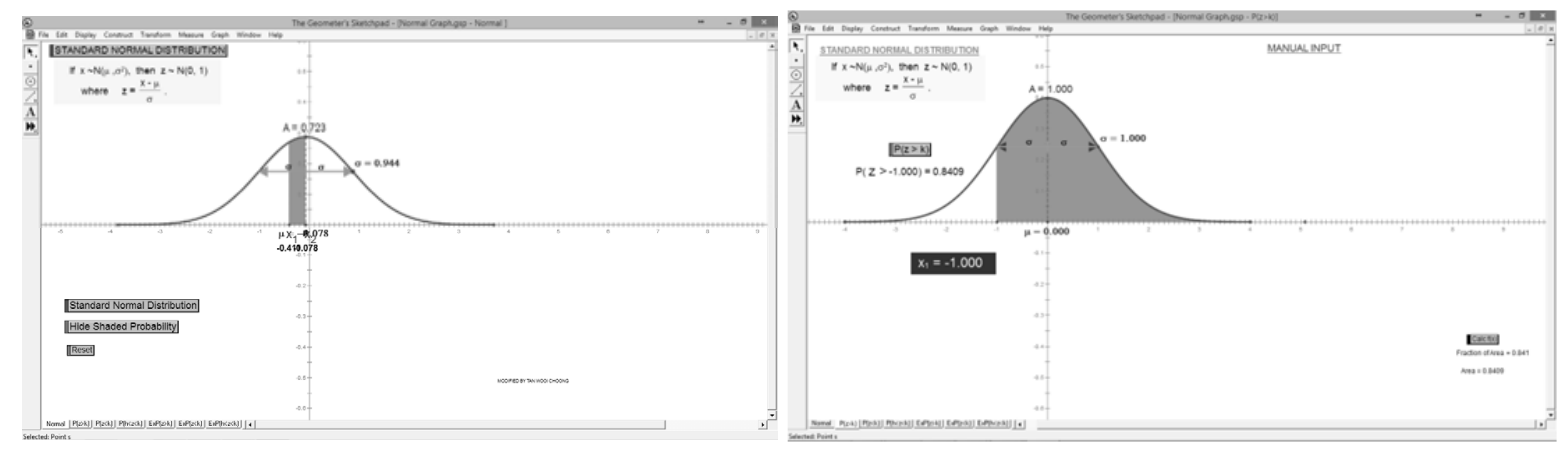

Figure 1: Exploring Standard Normal Distribution Using GSP 


\section{Case 2: GeoGebra}

In the many of the training programmes that have been conducted in the past, a perennial problem that we have encountered is getting participants to share what they have learned in the course with their colleagues and educators in their country. Another main challenge was getting funds to buy the software involved. This led the Centre to explore other equivalent alternatives. GeoGebra is one alternative source for Dynamic Mathematics Software for learning and teaching of Mathematics at all levels, especially since it is an opensource software. Besides that, there are also easily available ready-made resources which can be downloaded and adopted or adapted for one's own use.

GeoGebra was first introduced in our biannual conference, Conference on Science and Mathematics Education known as CoSMEd and then it was introduced as a regular topic in our courses and workshops. We have not only shared GeoGebra with teachers and educators in the Southeast Asian region but also beyond. Among some of these countries that the Centre has successfully introduced GeoGebra to are Iran, Bangladesh, Afghanistan, Nepal and Bhutan.

Figure 2 shows one sample of a participant's work. In this example, students are to determine the relationship between the area of the triangle AEF and that to the smaller square CFGE. The points A, B E are movable and these allowed the students to explore and make conjectures.

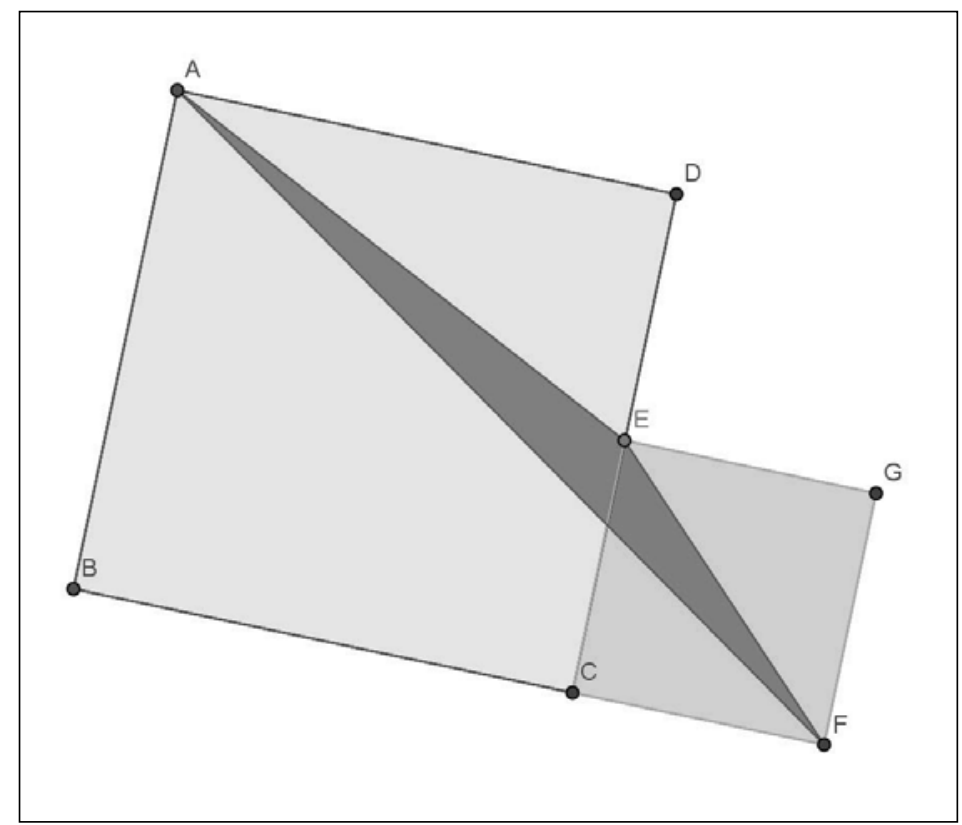

Figure 2: The Relationship Between the Area of the Triangle and the Area of the Smaller Square 
Normally, after the end of the workshops or courses, participants are required to provide feedback. For the use of GeoGebra, the majority of participants indicated the ease and user-friendliness of this software. Many of these first time users also indicated their request to learn more on using this software in teaching mathematics and this topic recorded the highest increase in the mean value when compared to the other topics in the course. It was also one of the topics that the participants managed to share with their colleagues back home as indicated in their multiplier effect report.

\section{Case 3: Autograph}

Autograph is a dynamic programme that operated in 3 modes, namely; (i) 1D-Statistic \& Probability, (ii) 2D-Graphing, coordinates, transformations and bivariate data; and, (iii) 3D- Graphing, coordinates and transformation. Autograph is designed to help teachers and pupils visualise mathematics at secondary to college level, using dynamically linked 'objects'. It is one of the topics shared in a customised course where the participants requested it. Feedback from our evaluation indicated high mean value for the construct that measured participants' satisfaction while using this technological tool.

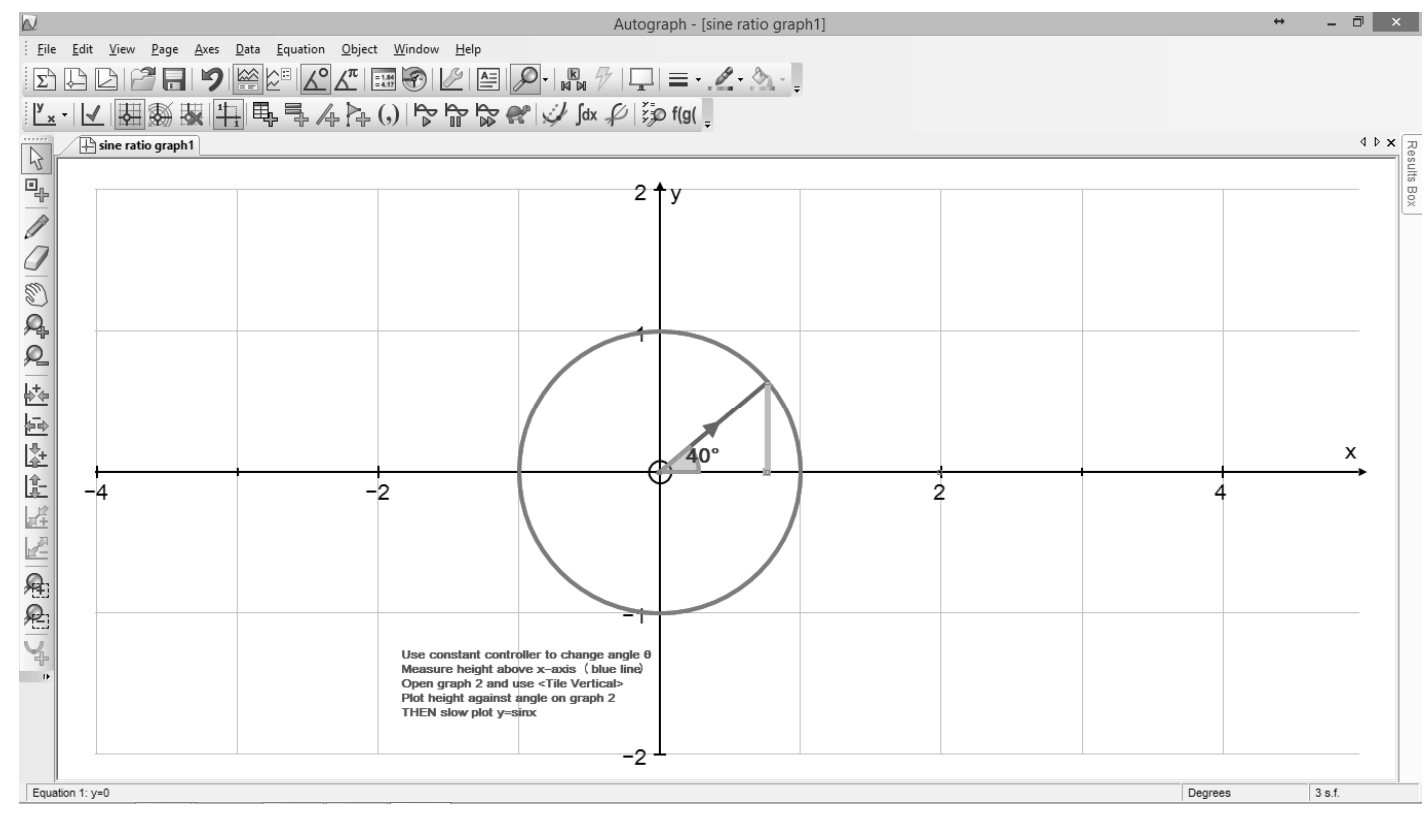

Figure 3: Exploring The Sine Ratio Graph Using Autograph

\section{Case 4: MathDisk}

MathDisk is a mathematical tool that can be used to build highly integrative, interactive and dynamic $2 \mathrm{D}$ or $3 \mathrm{D}$ worksheets. It helps to bring complex concepts to life when students learn through building their own models. 


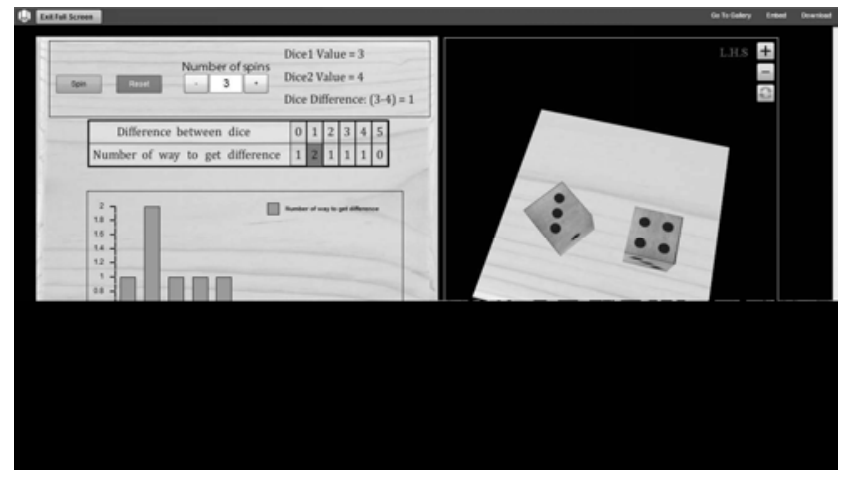

Figure 4: Rolling Two Dice Using MathDisk

Its interface encourages the exploration, construction and evaluation of mathematical models and simulations. The worksheets created with MathDisk can contain multiple graph sheets, equation editors, annotations and a flexible layout which can deliver multimedia-rich interactive version of the textbook which are identical to the text book material. MathDisk also introduces a tool called 'Robo Compass'. This tool provides an opportunity to teach and learn geometry as one would do while using a physical straightedge, compass and protractor. MathDisk is yet to be introduced as a topic and the Centre is considering introducing it in its next fiscal year courses.

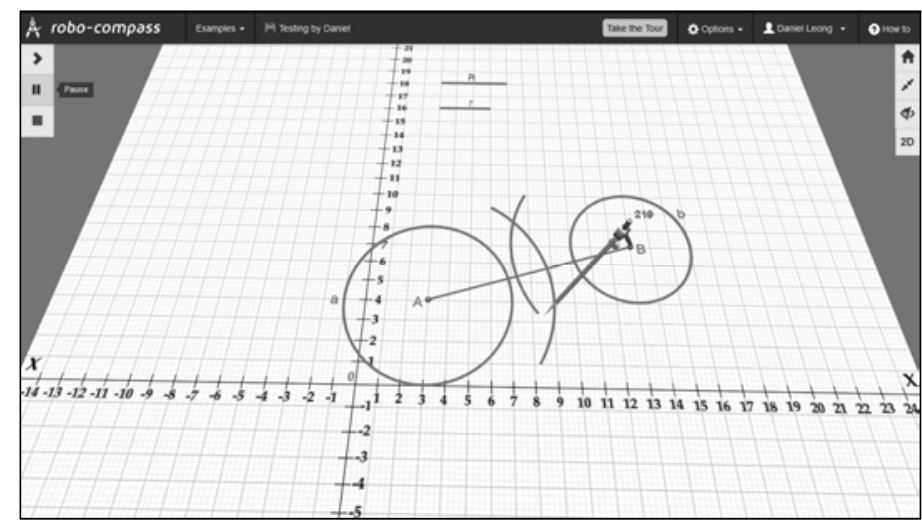

Figure 5: Construction with Robo Compass

\section{Case 5: Camtasia}

Camtasia provides teachers the tools to record their computer screen and then turn those recordings into videos. It provides a lot of interesting and attractive features in a fluid interface that makes creating screen capture videos and processing them quickly without much hassle. This technology tool allows users to set the programme to record either the screen or a PowerPoint presentation. Once the user has set the screen to capture a recording in the desired manner, the user can proceed to utilise the various tools included in the 
programme to create a complete video. These include multiple Transition Options, Voice Narration, a Zoom and Pan Effect, Cursor Effects, Captions, Quizzing, and more. The user can also use built-in tools to enhance and improve the audio quality of their voice recording.

Camtasia was introduced to a school near the Centre as part of their staff professional development programme and since then the school has been utilising it to produce videos of their teachers teaching with PowerPoint and other media. These videos were used during lessons when teachers were not present in the class. In this way, students did not miss any lessons or topics.

Some teachers used part of the videos created for the students to review whenever they were unsure of what they had learned in class. These teachers have successfully taken the first step to flipping their classroom and the Training Programme Division of SEAMEO RECSAM is proud in being a part of this transformation in the Malaysian education system.

\section{Case 6: Concerto}

Concerto is an open source on-line adaptive testing that was developed by the Psychometrics Centre of University of Cambridge and can be accessed from https://code.google.com/p/concerto- platform/. It can be used to develop a simple adaptive test. The test is designed by using $\mathrm{R}$ script. A table is used to store the data in the form of items, their responses and their difficulty level or any other item parameters depending on the parameter model stipulated in the Item Response Theory. The HTML template is used to create introduction template, item template and feedback template and is used to present as it is to the test takers. The scores are calculated as the test takers advance into the test.

Computer Adaptive Testing (CAT) has gained recognition as a test that is tailored to the test taker's ability. The design of CAT allows pre-calibrated items to be administered from an item bank, hence rendering itself as a customised test that continuously re-estimates the test taker's ability with improved precision of person measure. Since the selection of item difficulty is matched to person ability, the iterative process will converge to provide accurate, reliable and valid measures of person ability (Linacre, 2000). As items are individually paced, there is no need for the test takers to be presented with irrelevant items that are easy or difficult, hence reduces and eliminates 'unwanted' behaviour like boredom, fatigue, test anxiety and frustration. CAT provides immediate scoring and feedback to the test takers and 
cuts down testing time by half (Russel, 2006). In addition, administrating equivalently challenging items reduces over-exposure of items and thus increases test security. Cost of administrating tests is cut down as the need for hiring and training invigilators does not arise, which also reduces measurement error. Besides test takers, CAT also benefits test developers and test publishers as experimental items can be simultaneously validated with testing and, test revision is less strenuous since adding or removing of items does not contribute to test reliability (Rudner, 1998).

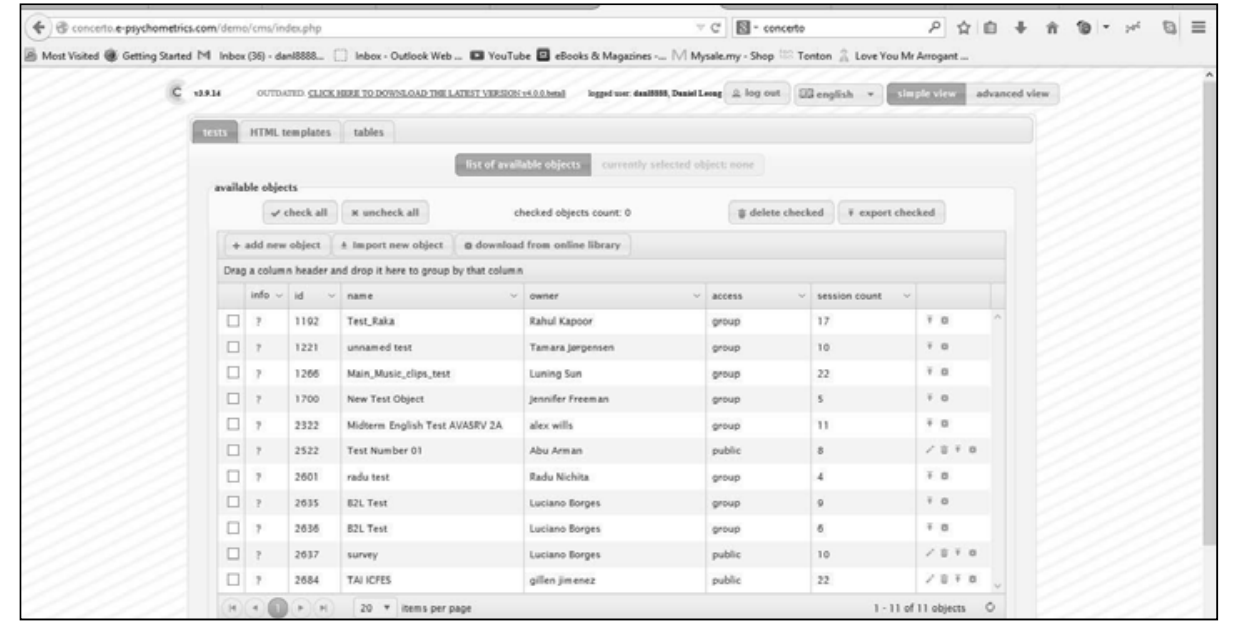

Figure 6: Concerto Interface

Concerto was introduced to a cohort of 12 secondary teachers as part of their fourweek in-service course. The teachers were guided through hands-on activities to design a simple test that consisted of Mathematics questions. A qualitative study was conducted after the training session. The results indicated the participants strongly agreed that Concerto was an ideal method of assessing students (mean= 4.21 out of 5). The participants felt that on-line adaptive testing was an effective, time- saving and useful mechanism in assessing students as it could accurately estimate students' ability. They expressed their satisfaction in using Concerto as a platform to conduct adaptive testing which they aimed to use in their classes after the course. The participants agreed that Concerto: Helped them to be more effective in assessing their students; Was more productive than paper-pencil test; Gave them more control in assessing their students; Saved time when in assessing students; Fulfilled their expectations about the purpose of an assessment; Was useful in assessing students; Gave accurate details about their students' ability; Was the correct way to assess students as it is based on students' ability. 


\section{Summary and Discussion}

This paper has provided selected educational technology tools that were introduced to the participants in our courses and workshops conducted in the SEAMEO RECSAM. Knowledge on incorporating other tools such as the Graphic Calculators, Interactive Whiteboard, tablets and mobile phones are disseminated during the training programmes at the Centre but these gadgets are not discussed here. These technology tools provide affordances to change the way mathematics is taught and learnt; from an extensively teacher directed activity to a more student centred exploratory tool. We also need to be reminded that each and every educational technology has its own strengths and weaknesses. At the end of the day, it is still the teachers who use these tools and are the most essential element in making the difference in the lives of students. The Centre will continue to find means to update the teachers and educators specifically in this region to keep abreast of the important educational technology developments that are taking place in the educational arena. 


\section{References}

Battista, M. \& Borrow, C. (1997). Shape Makers: A computer microworld for promoting dynamic imagery in support of geometric reasoning. Proceedings of the Nineteenth Annual Meeting, North American Chapter of the International Group for the Psychology of Mathematics Education, (Volume 2, pp. 571-578).

Finzer, W.F. \& Bennett, D.S. (1995). Technology Tips: From Drawing to Construction with the Geometer's Sketchpad. Mathematics Teacher, 88(5), 428.

Furner, J. M., \& Marinas, C. A. (2007). Geometry sketching software for elementary children: Easy as 1, 2, 3. Eurasia Journal of Mathematics, Science \& Technology Education, 3(1) 83-91.

Giamatti, C. (1995). Conjectures in Geometry and the Geometer's Sketchpad. Mathematics Teacher, 88(6), 456-458.

Harrison, C., Comber, C., Fisher, T., Haw, K. Lewin, C., Lunzer, E., \& Watling, R. (2002).The impact of Information \& Communication Technologies on pupil learning and attainment. Conventry, UK: Becta. Retrieved from http://partners.becta.org.uk/page_documents/research/ImpaCT2_strand1_bw.pdf.

Linacre, J.M. (2000). Computer-adaptive testing: A methodology whose time has come. Retrieved from http://www.rasch.org/memo69.pdf.

Rudner, L. (1998). An online, interactive, computer adaptive testing mini tutorial. ERIC Clearinghouse on Assessment and Evaluation.

Russell, M. (2006). Technology and assessment: The tale of two interpretations. United States of America: Information Age Publishing Inc.

Sinclair, N. \& Jackiw, N. (2005). Understanding and Projecting ICT Trends. In S. JohnstonWilder and D. Pimm (Eds.), Teaching Secondary Mathematics Effectively with Technology, (pp. 235-252). Berkshire, England: Open University Press.

Warabhorn, P., Devadason, R. P., Wahyudi, Cheah, U. H., \& Teoh, B. T. (Eds.). (2012). Teachers' Use of the Geometer's Sketchpad in Malaysian Secondary Schools: A Survey Report. Malaysia: Penang. SEAMEO RECSAM. 